\title{
RANCANG BANGUN ENERGI KINCIR ANGIN \\ PUTARAN RENDAH TIPE Multiblade Hawt \\ UNTUK IRIGASI PERTANIAN
}

Oleh:

ANANG SUPRIADI SALEH dan YULI HANANTO *)

\begin{abstract}
ABSTRAK
Permasalahan yang banyak mendapat perhatiaan nasional saat ini dan masa yang akan datang diantaranya adalah masalah ketahanan pangan dan konservasi energi. Pada lahan pertanian tadah hujan tidak mempunyai irigasi teknis, hal ini banyak kita jumpai di daerah pesisir sehingga pengelolaannya belum optimal, pada saat musim kemarau banyak petani membuat sumur-sumur dan menaikkan air tersebut dengan pompa motor bakar, sejak kenaikan BBM beberapa waktu yang lalu, petani mulai mengeluh karena biaya operasional dan perawatannya lebih mahal apalagi nantinya terjadi kenaikan BBM lagi, bahkan saat ini banyak lahan tadah hujan tidak dikelola pada saat musim kemarau, padahal di daerah pesisir Jawa termasuk lokasi penelitian mempunyai banyak potensi energi angin pada saat musim kemarau dengan kecepatan angin antara 2,5 sampai $7 \mathrm{~m} / \mathrm{dt}$ dan bertiup sepanjang hari dari jam 08.00 sampai dengan jam 16.00.

Tujuan jangka panjang penelitian ini adalah bahwa dengan adanya paket teknologi Kincir Angin Tipe Multiblade HAWT Untuk Aplikasi Pompa Irigasi Daerah Tadah Hujan mampu memberdayakan masyarakat Petani di daerah tadah hujan pada saat musim kemarau khususnya di daerah pesisir sehingga mendukung program ketahanan pangan dan konservasi energi karena tidak hanya bergantung pada energi fosil yang semakin langka.

Pendekatan desain untuk merancang kincir angin ini dilakukan melalui beberapa tahapan, antara lain; Kajian pustaka dan lapang, pengambilan dan analisa data dasar, Pembuatan rancangan dan pengujian. metode perancangan menggunakan metode yang disusun oleh Gerhardt Pahl dan Wolfgang Beitz yang dipaparkan dalam buku Engineering Design. Pengujian meliputi pengujian struktural dan fungsional di Laboratorium. Setelah itu di lakukan pengujian lapang (uji adaptasi, fungsional, dan verifikasi). Kemudian untuk penyempurnaan dilakukan modifikasi-modifikasi dan pengujian kembali.

Hasil penelitian menunjukkan bahwa paket teknologi Kincir Angin Tipe Multiblade HAWT, mempunyai daun 6 buah, tinggi menara $6 \mathrm{~m}$, total head pemompaan $7 \mathrm{~m}$. Kecepatan angin rata-rata $2,5 \mathrm{~m} / \mathrm{dt}, 22 \mathrm{rpm}$, pompa menghasilkan debit air 4 liter/menit, sedangkan pada kecepatan angin diatas $4 \mathrm{~m} / \mathrm{dt}$, $40 \mathrm{rpm}$ mampu menghasilkan debit air 8 liter/menit yang digunakan untuk irigasi daerah tadah hujan. Kincir Angin tersebut menambah kapasitas teknologi untuk pengelolaan lahan tadah hujan, dengan harapan dapat berfungsi dengan baik dan berdayaguna untuk memompa air dari sumur ke lahan pertanian dan harganya terjangkau oleh masyarakat petani. Selain itu menguatkan pemberdayaan masyarakat di daerah lahan tadah hujan khususnya di daerah pesisir yang saat ini hanya mengandalkan kegiatan usaha tani pada musim hujan.
\end{abstract}

Kata kunci: Kincir, Angin, Multiblade, Irigasi, Pertanian 


\section{PENDAHULUAN}

Lahan kering dan lahan tadah hujan banyak terdapat di Jawa Timur khususnya di daerah pesisir yang tidak mempunyai irigasi teknis, umumnya petani mengusahakan lahan sekali setahun yaitu pada musim hujan dengan tanaman semusim. Selain itu di musim kemarau sebagian besar lahan tidak diusahakan karena akan mengalami kekurangan air. Pemecahan permasalahan tersebut telah dilakukan melalui pengembangan sistem irigasi lahan kering skala kecil dengan memanfaatkan potensi airtanah dangkal yang dapat dimanfaatkan oleh petani. Lahan kering dan tadah hujan tersebut merupakan tumpuan petani untuk meningkatkan pendapatannya melalui usahatani baik tanaman pangan maupun hortikultura.

Pada musim kemarau, tanaman yang tidak diairi produktivitasnya tidak lebih dari 2 ton/ha. Dengan memberikan air irigasi sebagai suplesi pada fasefase tertentu pertumbuhan tanaman yang sensitif maka produktivitas tanaman dapat mencapai 4 ton/ha. Namun demikian petani harus mengoperasikan pompa selama sekitar 16,5 jam untuk setiap ton produksi tanaman. Dengan mengoptimalkan pola tanam dan meningkatkan intensitas pertanaman maka keuntungan yang diperoleh oleh petani akan lebih besar lagi untuk setiap luasan lahan yang diusahakan.

Pada saat ini penggunaan pompa motor bakar banyak mengalami kendala, sejak kenaikan BBM beberapa waktu yang lalu, petani mulai mengeluh karena biaya operasional dan perawatanna lebih mahal apalagi nantinya terjadi kenaikan BBM lagi, bahkan saat ini banyak lahan tadah hujan tidak dikelola pada saat musim kemarau, padahal di daerah pesisir Jawa tersebut mempunyai banyak potensi energi angin pada saat musim kemarau dengan kecepatan angin antara 2,5 sampai $7 \mathrm{~m} / \mathrm{dt}$ dan bertiup sepanjang hari dari jam 08.00 sampai dengan jam 17.00 .

Penggunaan kincir angin untuk memompa air tanah tersebut sangat nyata dalam meningkatkan intensitas pertanaman dari $100 \%$ (1 kali/tahun) menjadi $300 \%$ (tiga kali/tahun). Indonesia adalah negara yang memiliki sumber daya energi yang sangat melimpah, salah satunya adalah sumber energi angin. Indonesia yang merupakan negara kepulauan dan salah satu Negara yang terletak di garis khatulistiwa merupakan faktor, bahwa Indonesia memiliki potensi energi angin yang melimpah.

Pada dasarnya angin terjadi karena ada perbedaan suhu antara udara panas dan udara dingin. Di daerah katulistiwa, udaranya menjadi panas mengembang dan menjadi ringan, naik ke atas dan bergerak ke daerah yang lebih dingin. Sebaliknya daerah kutub yang dingin, udara menjadi dingin dan turun ke bawah. Dengan demikian terjadi perputaran udara berupa perpindahan udara dari kutub utara ke garis katulistiwa menyusuri permukaan bumi dan sebaliknya suatu perpindahan udara dari garis katulistiwa kembali ke kutub utara, melalui lapisan udara yang lebih tinggi. Potensi energi angin di Indonesia cukup memadai, karena kecepatan angin rata-rata berkisar 2,5 $7 \mathrm{~m} / \mathrm{s}$. Hasil pemetaan Lembaga Penerbangan dan Antariksa Nasional (LAPAN) pada 120 lokasi menunjukkan, beberapa wilayah memiliki kecepatan angin di atas $5 \mathrm{~m} /$ detik, masing-masing Nusa Tenggara Timur, Nusa Tenggara Barat, Sulawesi Selatan, dan Pantai Selatan Jawa.

Salah satu pemanfatan energi angin adalah penggunaan turbin angin yang banyak digunakan untuk kebutuhan pertanian, seperti untuk menggerakkan pompa untuk keperluan irigasi, serta kebutuhan akan energi yaitu sebagai pembangkit listrik energi angin. Penelitian ini secra khusus bertujuan untuk mengembangkan kincir angin angin tipe multiblade HAWT agar menghasilkan daya dan debit air irigasi yang optimal, mudah dalam pembuatan dan pengoperasiaannya, serta harganya terjangkau oleh masyarakat petani.

Sehingga penelitian ini mampu memberdayakan masyarakat petani di daerah lahan tadah hujan untuk mendukung ketahanan pangan dan mengembangkan teknologi konservasi energi yang ramah lingkungan dan tidak hanya bergantung pada energi fosil. 
Kincir angin pada penelitian ini bekerja dengan sistem poros horisontal dan menggunakan blade cekung enam buah (model of multiblade HAWT) untuk menghasilkan putaran dan daya penggerak yang ditransmisikan ke pompa air, kemudian energi yang dihasilkan digunakan untuk penggerak pompa air irigasi.

\section{LANDASAN TEORI}

Beberapa penelitian yang telah melakukan penelitian terkait ilmu yang menyangkut tentang turbin angin, antara lain:

Bambang setioko (2007), Kenaikan harga BBM mendorong masyarakat untuk mencari alternative baru yang murah dan mudah didapat untuk mendapatkan tenaga mekanik menjadi tenaga listrik. Tenaga angin merupakan tenaga gerak yang murah dan mudah didapat, sehingga hal ini dijadikan penelitian dan dimanfaatkan untuk tenaga penggerak generator listrik sehingga menghasilkan arus listrik. Teknik pengolahan dan analisis data dalam pembuatan turbin angin ini dibuat dengan mengambil data jumlah kipas, besarnya sudut, kecepatan angin, dan jumlah putaran. Analisis regresi digunakan sebagai metode untuk menyusun hubungan fungsional antara dua variable yaitu variable bebas dan tak bebas. Dengan konstruksi tinggi tiang 9 meter, dimensi kipas terdiri dari empat daun dengan diameter $3 \mathrm{~m}$, lebar $1,30 \mathrm{~m}$ dan tinggi $2,50 \mathrm{~m}$ yang terbuat dari lembaran alumunium. Putaran kipas dipercepat 20 kali (1:20) untuk memutar dynamo ampere dan dapat mengisi strum accu sehingga accu mampu memutar dynamo DC dan dynamo AC ikut berputar menghasilkan listrik. Arus listrik yang dihasilkan sekitar \pm 1500 watt untuk waktu \pm 30 menit

$$
\text { Sulistyo atmadi (2008), }
$$

mewakili Lembaga Penerbangan Dan Antariksa Nasional (LAPAN) meneliti tentang pengembangan metode parameter rotor turbin angin sumbu vertikal tipe multiblade HAWT. Penelitian ini dikembangkan dengan metode penentuan parameter awal rotor turbin angin sumbu vertical tipe multiblade HAWT. Dengan daya dan kecepatan angin tertentu, maka kisaran luas, diameter, tinggi, dan kecepatan putar rotor dapat diketahui. Luas rotor sangat dipengaruhi oleh koefisien daya.

$$
\text { Kecepatan putaran rotor }
$$
rancangan dapat dihitung setelah diameter rotor dihitung dan Tip Speed Ratio ditentukan. Penelitian ini menggunakan ratio diameter terhadap tinggi masing-masing 0,$1 ; 0,8 ; 0,8$. Hasilnya berupa table daya, kecepatan angin, luas rotor, diameter, tinggi serta kecepatan putar dapat digunakan sebagai rancangan awal turbin angin Multiblade HAWT bagi para pemula karena turbin angin ini dapat dibuat secara sederhana.

\section{Sistem Konversi Energi Angin (SKEA)}

Sistem konversi energi angin merupakan suatu sistem yang bertujuan untuk mengubah energi potensial angin menjadi energi mekanik poros oleh rotor untuk kemudian diubah lagi oleh alternator menjadi energi listrik. Prinsip utamanya adalah mengubah energi listrik yang dimiliki angin menjadi energi kinetik poros. Besarnya energi yang dapat ditransferkan ke rotor tergantung pada massa jenis udara, luas area dan kecepatan angin. Hal ini selanjutnya akan dibahas melalui persamaan-persamaan.

Energi kinetik untuk suatu massa angin $m$ yang bergerak dengan kecepatan $v$ yang nantinya akan diubah menjadi energi poros dapat dirumuskan sebagai berikut:

$$
\mathrm{E}=0.5 \mathrm{mv}^{2}
$$

(Eric Hau, Wind Turbines Fundamentals $2005: 81$ )

\section{Dimana:}

$m$ : massa udara yang bergerak $(\mathrm{kg})$

$v$ : kecepatan angin $(\mathrm{m} / \mathrm{s})$

Energi kinetik yang terkandung dalam angin inilah yang ditangkap oleh turbin angin untuk memutar rotor.

Dengan menganggap suatu penampang melintang $\mathrm{A}$, dimana udara dengan kecepatan $v$ mengalami pemindahan volume untuk setiap satuan waktu, yang disebut dengan aliran volume V sebagai persamaan:

$$
\mathrm{V}=\mathrm{vA}
$$

(Eric Hau, Wind Turbines

Fundamentals $2005: 81$ )

Dimana:

$V$ : laju volume $\left(\mathrm{m}^{3} / \mathrm{s}\right)$

$v:$ kecepatan angin $(\mathrm{m} / \mathrm{s})$ 
$A$ : luas area sapuan rotor $\left(\mathrm{m}^{2}\right)$

Sedangkan aliran massa dengan kecepatan udara $p$ sebagai:

$\mathrm{m}=\rho \mathrm{Av}$

(Eric $\mathrm{Hau}$ Wind Turbines

Fundamentals $2005: 82$ )

Persamaan-persamaan diatas menunjukkan energi kinetik dan aliran massa yang melewati suatu penampang melintang A sebagai energi $\mathrm{P}$ :

$\mathrm{P}=0.5 \rho \mathrm{A} \mathrm{v}^{3}$

(Eric Hau, Wind Turbines

Fundamentals $2005: 82$ )

Dimana:

$\mathrm{P}$ : daya mekanik (W)

$v:$ kecepatan angin $(\mathrm{m} / \mathrm{s})$

$\rho$ : densitas udara ( $\rho$ rata-rata $: 1,2$ $\mathrm{kg} / \mathrm{m}^{3}$ )

Karena setiap jenis turbin angin mempunyai karakteristik aerodinamika yang unik, maka faktor daya sebagai fungsi dari TSR untuk setiap jenis turbin angin juga berbeda-beda. Dengan memasukkan faktor daya Cp, sebagaimana dijelaskan sebelumnya, gaya mekanik aktual yang dapat diperoleh dari energi kinetik pada angin menjadi:

$$
\begin{aligned}
& \mathrm{P}=\mathrm{Cpr} 0.5 \rho \mathrm{A} \mathrm{v}^{3} \\
& \text { (Eric Hau, Wind Turbines }
\end{aligned}
$$

Fundamentals 2005 : 98)

Parameter

$$
\text { utama }
$$

yang mempengaruhi $\mathrm{Cp}$ adalah: jumlah bilah sudu, panjang chord bilah sudu, karakteristik aerodinamis bilah sudu, NREL menambahkan kemampuan sebuah SKEA juga dibatasi oleh rugi-rugi pada generator dan sistem transmisi.

\section{Tip Speed Ratio}

Tip speed ratio (rasio kecepatan ujung) adalah rasio kecepatan ujung rotor terhadap kecepatan angin bebas. Untuk kecepatan angin nominal yang tertentu, tip speed ratio akan berpengaruh pada kecepatan putar rotor. Turbin angin tipe lift akan memiliki tip speed ratio yang relatif lebih besar dibandingkan dengan turbin angin tipe drag. Tipe speed ratio dihitung dengan persamaan:

\section{$\lambda=\pi D n / 60 v$}

(Eric Hau, Wind Turbines

Fundamentals 2005 : 94)

Dengan:

$$
\begin{aligned}
& \lambda=\text { tipe speed ratio } \\
& \mathrm{D}=\text { diameter rotor }(\mathrm{m}) \\
& \mathrm{n}=\text { putaran rotor }(\mathrm{rpm}) \\
& \mathrm{v}=\text { kecepatan angin }(\mathrm{m} / \mathrm{s})
\end{aligned}
$$

\section{Pemilihan Sistem Transmisi Daya}

Ketika putaran rotor dan daya motor sudah ditentukan, maka generator yang digunakan dipilih. Generator yang tersedia di pasaran memiliki karakteristik yang berbeda satu sama lain. Setiap generator memiliki kondisi kerja masing-masing.

Untuk meneruskan daya yang dihasilkan rotor ke generator, perlu sistem transmisi yang konfigurasinya disesuaikan dengan kebutuhan daya yang ditransmisikan, putaran, dan konfigurasi turbin angin. Sistem transmisi daya dapat dikelompokkan menjadi tiga kelompok menurut rasio putaran masukan dan keluarannya yaitu:

1. Direct drive

2. Speed Reducing

3. Speed Increasing

Direct Drive yang dimaksud adalah transmisi daya langsung dengan menggunakan porors dan pasangan kopling. Yang penting dalam sistem transmisi direct drive adalah tidak ada penurunan atau peningkatan putaran. Sistem transmisi speed reducing adalah sistem transmisi daya dengan penurunan putaran, putaran keluar lebih rendah daripada putaran masuk. Sistem transmisi ini digunakan untuk meningkatkan momen gaya. Yang terakhir adalah sistem transmisi speed increasing, yaitu putaran keluar lebih tinggi dari putaran masuk, terjadi kenaikan putaran dengan konsekuensi momen gaya keluar menjadi lebih kecil.

Pada penerapannya, sistem transmisi direct drive hanya menggunakan poros dan kopling jika diperlukan. Konstruksi direct drive lebih sederhana dibandingkan yang lainnya dan tidak memerlukan banyak ruang. Sedangkan untuk penerapan sistem transmisi speed reducing dan speed increasing diperlukan mekanisme pengubah putaran seperti pasangan roda gigi, atau sabuk dan puli.

Turbin angin yang putaran rotornya berada dalam selang putaran kerja generator, maka transmisi daya yang digunakan adalah direct drive, rotor menggerakkan generator secara 
Anang Supriyadi S dan Yuli Hananto, Rancang Bangun Energi Kincir Angin Putaran Rendah Tipe Multiblade Hawt Untuk Irigasi Pertanian

langsung. Sedangkan transmisi speed increasing karena pada umumnya putaran yang diperlukan generator lebih tinggi daripada putaran rotor.

$$
\text { Generator adalah peralatan }
$$

elektronika mekanik yang mengubah besaran energi mekanik menjadi energi listrik arus bolak-balik. Kebanyakan Generator menggunakan rotating magnetic field, akan tetapi adakalanya alternator linear digunakan. Pada prinsipnya, setiap generator AC dapat disebut sebagai alternator, akan tetapi istilah tersebut sering disama artikan dengan mesin putaran kecil yang dikendalikan oleh automotif atau mesin pembakaran internal. Salah satu contoh, alternator digunakan sebagai mesin pembangkit listrik arus bolak-balik dengan tenaga turbin uap yang sering dikenal sebagai turbo-alternator.

\section{METODE PENELITIAN}

Penelitian ini rencananya akan dilaksanakan pada bulan Agustus 2012 sampai dengan Maret 2013. Pembuatan komponen rancang bangun kincir angin dan pengujian laboratorium di kerjakan di Bengkel Politenik Negeri Jember sedangkan pengujian lapang dilaksanakan di daerah lahan tadah hujan di sekitar pesisir Kabupaten Situbondo.

\section{A. PENDEKATAN DESAIN}

Berdasarkan metode Gerhardt Pahl dan Wolfgang Beitz, maka spesifikasi yang di buat terdiri dari dua kategori umum yang harus dimiliki oleh unit kincir angin multiblade HAWT bertingkat ini, yaitu:

- Keharusan (Demands) disingkat D, yaitu syarat mutlak yang harus dimiliki kincir, bila tidak terpenuhi maka mesin merupakan solusi yang tidak diterima

- Keinginan (Wishes) disingkat W, yaitu syarat yang masih dapat dipertimbangkan keberadaannya agar jika mungkin dapat dimiliki oleh kincir angin yang dirancang.

Berikut adalah daftar spesifikasi dari mesin yang dimaksud:

\begin{tabular}{|c|c|c|}
\hline KATAGORI & \multicolumn{2}{|c|}{ KATAGORI KINCIR ANGIN MULTIBLADE HAWT } \\
\hline $\begin{array}{c}\text { D } \\
\text { W }\end{array}$ & PERSYARATAN & RESPONSIBILITAS \\
\hline $\begin{array}{l}\mathrm{D} \\
\mathrm{D} \\
\mathrm{D} \\
\mathrm{D}\end{array}$ & \begin{tabular}{ll}
\multicolumn{2}{l}{ GAYA } \\
1. & Mempunyai gaya gesek \\
2. & Mempunyai gaya tekan \\
3. & Mempunyai gaya puntir \\
4. & Terjadi gaya gesek dan tekan yang tetap \\
\end{tabular} & \\
\hline $\begin{array}{l}\mathrm{D} \\
\mathrm{D} \\
\mathrm{D} \\
\mathrm{D} \\
\mathrm{D}\end{array}$ & $\begin{array}{l}\text { KINEMATIKA } \\
\text { 1. Arah gesek tetap } \\
\text { 2. Arah tekan tetap } \\
\text { 3. } \quad \text { Arah gaya puntir } \\
\text { 4. } \quad \text { Mekanismenya mudah beroperasi } \\
\text { 5. } \quad \text { Menggunakan transmisi untuk keuntungan mekanis } \\
\end{array}$ & \\
\hline $\begin{array}{l}\text { D } \\
\text { D } \\
\text { D } \\
\text { W } \\
\text { D }\end{array}$ & $\begin{array}{l}\text { GEOMETRI } \\
\text { 1. Panjang Blade } 150 \mathrm{~cm} \\
\text { 2. Lebar Blade sekitar } 25 \mathrm{~cm} \\
\text { 3. Jumlah blade } 6 \text { buah } \\
\text { 4. Dimensi dapat dirubah } \\
\text { 5. } \quad \text { Tinggi menara } 600 \mathrm{~cm} \\
\end{array}$ & \\
\hline $\begin{array}{l}\mathrm{D} \\
\mathrm{W}\end{array}$ & $\begin{array}{l}\text { ENERGl } \\
\text { 1. Mengunakan tenaga angin } \\
\text { 2. Debit pompa air } 8 \text { liter/menit }\end{array}$ & \\
\hline $\begin{array}{l}\text { D } \\
\text { D } \\
\text { W } \\
\text { D } \\
\text { D } \\
\text { D }\end{array}$ & $\begin{array}{ll}\text { MATERIAL } \\
\text { 1. } \\
\text { 2. } \text { Mudah didapat } \\
\text { 3. } \\
\text { 4. } & \text { Taik mutunanya terhadap korosi } \\
\text { 5. } & \text { Sesuai dengan standar umum } \\
\text { 6. } & \text { Memiliki umur pakai yang panjang }\end{array}$ & \\
\hline
\end{tabular}




\begin{tabular}{|c|c|}
\hline $\mathrm{D}$ & 7. Mempunyai sifat mekanis yang baik \\
\hline $\begin{array}{l}\text { D } \\
\text { W } \\
\text { D } \\
\text { D }\end{array}$ & $\begin{array}{ll}\text { ERGONOMI } \\
\text { 1. } & \text { Sesuai dengan kebutuhan } \\
\text { 2. } & \text { Mudah dipindahkan } \\
\text { 3. } & \text { Tidak bising } \\
\text { 4. } & \text { Mudah dioperasikan } \\
\end{array}$ \\
\hline $\begin{array}{l}\mathrm{D} \\
\mathrm{D} \\
\mathrm{W}\end{array}$ & $\begin{array}{ll}\text { PENGGUNAAN } \\
\text { 1. } \\
\text { 2. } & \text { Petunjuk pengoperasian mudah dimengerti } \\
\text { 3. } & \text { Petunjuk pengoperasian dalam bahasa Indonesia } \\
\end{array}$ \\
\hline $\begin{array}{l}\text { D } \\
\text { D } \\
\text { W }\end{array}$ & $\begin{array}{ll}\text { KESELAMATAN } \\
\text { 1. } \quad \text { Konstruksi harus kokoh } \\
\text { 2. } \quad \text { Bagian yang berbahaya harus ditutup } \\
\text { 3. } & \text { Tidak menimbulkan polusi } \\
\end{array}$ \\
\hline $\begin{array}{l}\text { D } \\
\text { D } \\
\text { D } \\
\text { W } \\
\text { W }\end{array}$ & $\begin{array}{ll}\text { PRODUKSI } \\
\text { 1. } & \text { Dapat diproduksi oleh bengkel kecil } \\
\text { 2. } & \text { Suku cadang mudah di dapat } \\
\text { 3. } & \text { Suku cadang murah } \\
\text { 4. } & \text { Biaya produksi relatif rendah } \\
\text { 5. } & \text { Dapat dikembangkan kembali } \\
\end{array}$ \\
\hline $\begin{array}{l}\text { D } \\
\text { D } \\
\text { W }\end{array}$ & $\begin{array}{ll}\text { PERAWATAN } \\
\text { 1. } \quad \text { Biaya perawatan murah } \\
\text { 2. } \quad \text { Perawatan mudah dilakukan } \\
\text { 3. } \quad \text { Perawatan secara berakala } \\
\end{array}$ \\
\hline $\begin{array}{l}\mathrm{D} \\
\mathrm{D}\end{array}$ & \begin{tabular}{|l} 
TRANSPORTASI \\
1. $\quad$ Mudah dipindahkan \\
2. $\quad$ Tidak memerlukan alat khusus untuk mengangkat
\end{tabular} \\
\hline
\end{tabular}

Dari urutan proses diatas, maka secara fungsional unit kincir angin multiblade HAWT memiliki komponen yang berfungsi sebagai berikut:

a. Blade kincir angin tipe multiblade HAWT

b. Penyangga

c. Bantalan Poros

d. Transmisi penerus daya dari poros blade kincir angin ke pompa air

e. Pemberat

f. Pompa torak.

\section{B. PENGUJIAN}

Setelah rancangan kincir angin dibuat kemudian dilakukan pengujian untuk mengetahui performance kincir tersebut. Pengujian di Laboratorium meliputi Uji Struktural dan Uji Fungsional. Uji struktural bertujuan untuk mengetahui kekuatan atau kekokohan tiap komponen atau bagian alat pada saat kondisi ada beban dan dioperasikan. Sedangkan uji fungsional bertujuan untuk mengetahui fungsi tiap komponen atau bagian-bagiannya, baik fungsi per bagian maupun fungsi secara terpadu kaitan antar beberapa komponen. Kemudian dilakukan pengujian di lapangan yang meliputi; uji adaptasi, uji fungsional, dan uji verifikasi.

\section{Pelaksanaan Pengujian Kincir Angin}

Alat :

- Stopwacth

- Tachometer

- Flow udara

- Ember

- Gelas ukur 
Anang Supriyadi S dan Yuli Hananto, Rancang Bangun Energi Kincir Angin Putaran Rendah Tipe Multiblade Hawt Untuk Irigasi Pertanian

\section{Bahan:}

$$
\text { - Kertas HVS }
$$

\section{Variable Pengujian}

Parameter yang diamati pada pengujian kincir angin ini adalah sebagai berikut :

- Kecepatan angin

- Diameter balde
- Jumlah blade

- Rpm blade

- Beda head pemompaan

- Diamter pompa torak

- Debit air

\section{Pengolahan data}

Dalam pengolahan data kemudian dihitung debit air yang dihasilkan oleh pompa torak pada kecepatan angin tertentu

\section{KONSEP RANCANGAN}

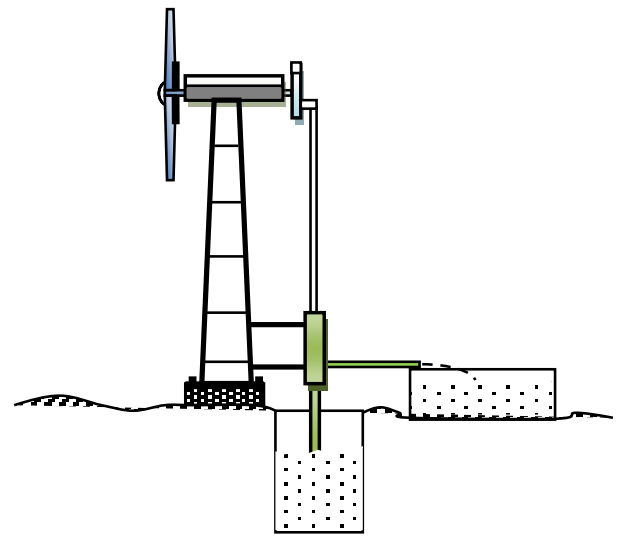

\section{Gambar 1. Konsep Rancangan Kincir Angin Multiblade HAWT}

\section{HASIL DAN PEMBAHASAN}

\section{A. Desain Fungsional}

Bagian-bagian atau komponen dan fungsi komponen mesin pemeras sari buah jeruk secara kontinyu ini antara lain :

$$
\begin{aligned}
& \text { 1. Penyangga } \\
& \text { Berfungsi } \\
& \text { penyangga beban dari beberapa } \\
& \text { komponen lain seperti blade, } \\
& \text { poros, bearing, kerangka poros, } \\
& \text { crank dan besi penarik, gaya } \\
& \text { sentrifugal dan gaya angin. } \\
& \text { Kerangka yang digunakan sudah } \\
& \text { kuat dan kokoh untuk menahan } \\
& \text { beban dari beberapa komponen } \\
& \text { pada saat kincir angin bekerja. } \\
& \text { 2. Blade }
\end{aligned}
$$

\begin{tabular}{lrr}
\multicolumn{2}{c}{ Berfungsi } & sebagai \\
pemutar poros & untuk \\
menggerakkan crank & dan \\
pompa torak. & Blade & yang
\end{tabular}

digunakan dapat berfungsi dengan baik dan daya yang digunakan sudah cukup untuk menggerakkan pompa dan menaikkan air.

3. Poros

$\begin{array}{cr}\text { Berfungsi } & \text { sebagai } \\ \text { penyalur tenaga } & \text { yang }\end{array}$ menghubungkan antara blade dan crank pompa air. Poros yang digunakan sudah cukup kuat untuk meneruskan putaran.

4. Bearing

Berfungsi bantalan poros agar putarannya dilanjutkan ke crank pompa. Bearing yang digunakan dapat berfungsi dengan baik dan kuat dalam menyalurkan putaran dari blade.

5. Crank 
Berfungsi meneruskan putaran untuk memutar engkol. Poros yang digunakan sudah kuat dan kokoh serta dapat menyalurkan putaran dengan baik.

6. Tuas Penarik

$$
\begin{aligned}
& \text { Berfungsi penyalur } \\
& \text { tenaga gerak dari crank } \\
& \text { menjadi gerak naik turun pada } \\
& \text { pompa torak. Tuas penarik } \\
& \text { dapat berfungsi dengan baik } \\
& \text { dan dapat menarik dan } \\
& \text { menekan tuas pompa torak. }
\end{aligned}
$$

7. Pompa Torak

$$
\begin{aligned}
& \text { Berfungsi menaikkan air } \\
& \text { dari sumur } \text { ke } \\
& \text { penampungan. Pompa torak } \\
& \text { berfungsi dengan baik dalam } \\
& \text { melakukan pemompaan air } \\
& \text { padabeda head } 7 \mathrm{~m} \text {. }
\end{aligned}
$$

8. Tension Klep

$$
\text { Berfungsi sebagai klep }
$$

searah aliran air yang

dipompakan. Tension klep

berfungsi dengan baik yaitu menghisap air yang masuk dan menahan kembalinya air, sehngga air masuk pada pipa pemasukan.

9. Pemberat

$$
\text { Berfungsi sebagai }
$$
penyeimbang gaya tarik pada saat langkah hisap dari pompa torak. Pemberat berfungsi dengan baik untuk menyeimbangkan tenaga putar dari blade.

\section{B. Desain Struktural}

Berdasarkan hasil pembuatan kincir angin diperoleh suatu bentuk mesin yang siap digunakan, perancangan ini dilakukan meliputi seluruh bagian yang ada pada kincir angin. Bagian-bagian tersebut meliputi :

1. Penyangga

$$
\text { Kerangka terbuat dari }
$$
besi siku 50. 50. 5 yang artinya besi siku tersebut mempunyai lebar sisi yang sama yakni $50 \mathrm{~mm}$ dan ketebalan $5 \mathrm{~mm}$. dimensi kerangka adalah panjang 100 $\mathrm{mm}$, lebar $100 \mathrm{~mm}$ dan tinggi $600 \mathrm{~mm}$. Kerangka juga dilengkapi dengan dudukan unit blade dan transmisi. Kerangka dirancang sedemikian rupa agar mampu menahan segala jenis bahan. Dalam fungsinya, kerangka sudah mampu menahan beban yang terjadi pada saat kincir angin bekerja.

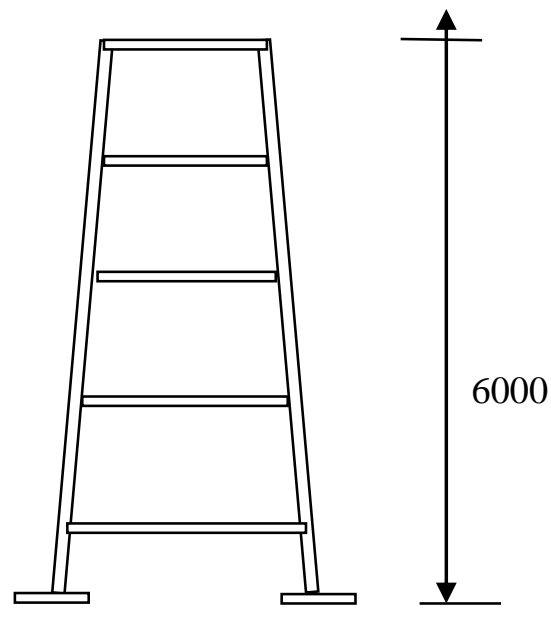


Anang Supriyadi S dan Yuli Hananto, Rancang Bangun Energi Kincir Angin Putaran Rendah Tipe Multiblade Hawt Untuk Irigasi Pertanian

2. Blade

Blade terbuat dari plat aluminium $1 \mathrm{~mm}$ dengan ukuran panjang $1500 \mathrm{~mm}$ dengan lebar 250 mm. Blade berbentuk melengkung untuk kekuatan terhadap gaya angin.

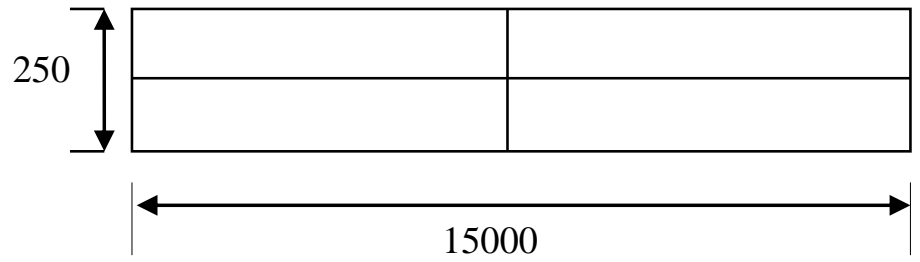

3. Poros

Poros terbuat dari besi as berdiameter $1,25 \mathrm{dim}$, dengan panjang $1000 \mathrm{~mm}$. Poros meneruskan putaran blade ke putaran crank. Pada poros tejadi gaya puntir dan tarik.

4. Bearing

Bearing yang digunakan jenis bearing duduk, ukurannya sesuai dengan ukuran poros dengan diameter dalam 1,25 dim.

5. Crank

Crank terbuat dari besi siku 5 x $5 \mathrm{~cm}$, berfungsi sebaga poros engkol untuk mengubah putaran radial ke putaran vertikal. Sehingga pada crak terdapat as penarik dan pemberat.

6. Tuas Penarik

Tuas penarik dibuat dari besi pipa 0,5 dim dengan panjang $5000 \mathrm{~mm}$. Tuas penarik menghubungkan crank dengan pompa torak.

7. Pompa Torak

Pompa torak terbuat dari pipa besi ukuran diamter 4 dim. Pompa torak bekerja untuk menaikkan air sumur ke bak penampungan. Debit air tergantung pada diameter pompa dan panjang langkahnya.

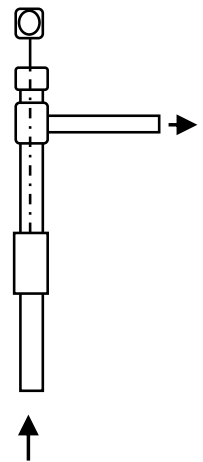


8. Tension Klep

$$
\text { Tension }
$$

digunakan

$$
\text { klep } \begin{array}{r}
\text { yang } \\
\text { adalah }
\end{array}
$$
berfungsi untuk menahan air kembali kebawah, selain itu berfungsi untuk menyaring air yang masuk.

9. Pemberat

Penggerak mula atau sumber putaran dari mesin pemeras sari buah jeruk ini menggunakan motor listrik 1 HP dengan putaran 1400 rpm. Motor listrik yang digunakan sudah mampu untuk memutar engkol dan melakukan pemerasan pada piston pengepres.

\section{Pengujian}

Hasil pengujian kincir ini menunjukkan bahwa secara struktural semua bagian mempunyai kontruksi yang kokoh, sedangkan secara fungsional setiap bagian dan secara terintegrasi berfungsi dengan baik.

\section{Pengoperasian Kincir Angin}

Cara pengoperasian kincir angin ini adalah sebagai berikut :

1. Sebelum dioperasikan, komponen kincir angin diinstal terlebih dahulu

2. Mur baut diperiksa dan dikencangkan bila perlu.

3. Gelas ukur dipersiapkan dan ditempatkan disaluran pengeluaran pompa air.

4. Stopwath dipersiapkan

5. Flow meter dipersiapkan

6. Blade dilepas ikatannya dan dibiarkan berputar.

7. Putaran blade akan menarik tuas pompa torak sehingga menghisap air pada sumur dan dislurkan ke bak penampung

Data Hasil Pengujian Kincir Angin Pada Bulan Oktober-Nopember 2012

\begin{tabular}{|c|l|c|}
\hline No & \multicolumn{1}{|c|}{ Parameter } & Pengukuran \\
\hline 1. & Kecepatan Angin & $2-7 \mathrm{~m} / \mathrm{det}$ \\
\hline 2. & Diamater blade & $3 \mathrm{~m}$ \\
\hline 3. & Jumlah blade & $6 \mathrm{buah}$ \\
\hline 4. & Rpm blade & $20-60$ \\
\hline 5. & Beda head pemompaan & $7 \mathrm{~m}$ \\
\hline 6. & Diameter pompa torak & $4 \mathrm{dim}$ \\
\hline 12. & Panjang langkah & $12 \mathrm{~cm}$ \\
\hline & & $\mathrm{V}=2,5 \mathrm{~m} / \mathrm{dt}, 22 \mathrm{RPM}$, \\
13. & Debit air & $\mathrm{Q}=4 \mathrm{miter} / \mathrm{menit}$ \\
& & $\mathrm{Q}=81 \mathrm{dt}, 40 \mathrm{RPM}$, \\
& &
\end{tabular}

D. Spesifikasi Kincir Angin yang dihasilkan

Spesifikasi kincir angin yang telah selesai dibuat ini adalah sebagai berikut :

Dimensi Penyangga: $1000 \mathrm{~mm} \times 1000 \mathrm{~mm} \times 6000 \mathrm{~mm}$

Diameter blade $\quad: 3000 \mathrm{~m}$

Jumlah blade : 6 buah

Putaran blade : $20-60 \mathrm{RPM}$

Kecepatan Angin $\quad: 2-7 \mathrm{~m} /$ detik

Panjang langkah pompa $: 120 \mathrm{~mm}$

Debit air pompa $\quad: 4-8$ liter/menit 
Anang Supriyadi S dan Yuli Hananto, Rancang Bangun Energi Kincir Angin Putaran Rendah Tipe Multiblade Hawt Untuk Irigasi Pertanian

\section{KESIMPULAN DAN SARAN}

\section{A. KESIMPULAN}

Berdasarkan hasil penelitian dapat disimpulkan bahwa:

1. Prototipe kincir angin mempunyai spesifikasi sebagai berikut:

\section{SPESIFIKASI:}

Dimensi Penyangga : $1000 \mathrm{~mm} \times 1000 \mathrm{~mm} \times 6000 \mathrm{~mm}$

Diameter blade $\quad: 3000 \mathrm{~m}$

Jumlah blade $\quad: 6$ buah

Putaran blade : $20-60 \mathrm{RPM}$

Kecepatan Angin $\quad: 2-7 \mathrm{~m} /$ detik

Panjang langkah pompa : $120 \mathrm{~mm}$

Debit air pompa $\quad: 4-8$ liter/menit

2. Faktor yang mempengaruhi kinerja kincir angin adalah kecepatan angin, ukuran dan jumlah blade, sudut blade, ukuran dan panjang langkah pompa torak.

\section{B. SARAN}

Perlu pengembangan kincir angin dengan transmsi putaran yang lebih cepat, kedalaman dan debit air yang lebih besar.

\section{DAFTAR PUSTAKA}

. LAPAN. JakartaAWS Scientific,Inc. (1996), Wind Resource Assessment Handbook, NREL, USA.

Dnv/Riso. (2002). Guidelines for Design of Wind Turbines 2nd Edition. Jydsk Centraltrykkeri, Denmark

Frereis L.L (1990), Wind Energy Conversion Systems, Prentice Hall, NY USA.
Jop Van Meel and Paul Smulders (1989), Wind Pumping, A Handbook, The World Bank, Washington, DC.

Nurtjahjomuljo. Rancang Bangun Generator Turbin Angin Tipe Aksial Kapasitas 200W. LAPAN. Jakarta

Sitompul R. (2011). Modul Pelatihan Penerapan Energi Terbarukan. PNPM Mandiri. Jakarta

Soepriono. (2011). Potensi dan Pengembangan Energi Angin di Indonesia 